\title{
THE STUDY OF ACTION THE OZONE IN THE SURGICAL TREATMENT OF INFLAMMATORY PROCESSES BY DIABETES MELLITUS
}

DOI: 10.36740/WLek202104113

\author{
Svitlana Y. Karatieieva, Nataliia Y. Muzyka, Karolina I. Yakovets, Oksana V. Bakun, Ksenia V. Slobodian \\ BUKOVINIAN STATE MEDICAL UNIVERSITY, CHERNIVTSI, UKRAINE
}

\begin{abstract}
The aim: was to improve the course of purulent wounds in diabetes by using physical therapies.

Materials and methods: we investigated 122 patients with diabetes mellitus and wound processes. We divided all patients on the two groups. Our study groups were 50 patients who had therapy by ozone together with other general treatment and surgery treatment (daily dressings, ointments and solutions). Our control groups were 72 patients, who had treated only by general methods and surgery treatment (daily dressings, ointments and solutions). The patients of our explore group had received intravenous injection of saline ozone solution together with other general treatment and surgery treatment (daily dressings, ointments and solutions).

Results: it had studied of indicators of oxidative modification of proteins, lipid peroxidation in blood plasma, antioxidant protection during this period, there were no significant changes in these parameters between the control and experimental groups. As the result of the study was found that the leukocyte index of intoxication in patients in the main and control groups was almost indistinguishable. Regarding the indexes of hematological index of intoxication, which decreased during the treatment of patients of the main group, and different from the patients of the control group, in which this indicator increased sharply. The result of the study of changes in the indicators of sorption capacity of erythrocytes showed that the level of sorption capacity of erythrocytes in patients in the main group during treatment, also decreased, compared with patients in the control group. Conclusions: Therefore, the use of ozone in the treatment of patients with complicated forms of diabetes does not cause a negative impact on the dynamics of homeostasis and indicators of the level of intoxication of the body. Ozone therapy has a beneficial effect on the course and wound process in patients with diabetes with purulent processes.
\end{abstract}

KEY WORDS: diabetes mellitus, wounds, physical methods, indices of homeostasis

Wiad Lek. 2021;74(4):884-886

\section{INTRODUCTION}

Diabetes is a disease that affects more than 425 million people in the worldwide. There are nearly 1.3 million patients in Ukraine, and it are increasing every year. Almost 104,000 Ukrainians have been diagnosed with diabetes for the first time in $2017-2 \%$ more than in 2016. [1,2]

During from ten to fifteen years, diabetes can be cause a great deal of damage to the whole body, especially if there are significant complications, even if all the requirements for treatment and diet are met. Most often, with this disease, the composition of the blood changes, which leads to chronic damage to all vital organs. The peripheral vessels, especially the lower extremities, suffer first of all, which leads to the occurrence of «diabetic foot» syndrome. In the treatment of this complication, it is important to use, along with drugs that adjust blood sugar and symptomatic treatment, as well as local treatment methods.

The treating diabetes and its complications is an extraordinary task. In this regard, it is important to study in detail the causes and course and various methods of treatment of diabetes, which makes it possible to detect the presence of certain activity of physical methods of treatment of this pathology. $[3,4]$.
Diabetic foot - is defeat of the feet of patients with diabetes in the form of purulent-necrotic processes, ulcers and bone and joint lesions, occurs against changes in the peripheral nerves, blood vessels, skin and soft tissues, bones and joints. It is a major cause of lower extremity amputations in patients with diabetes mellitus. There are vascular, nerve-trophic and mixed forms of diabetic foot. $[5,6,7]$.

The main processes in progression of inflammatory complications of wounds in ill by diabetes mellitus are exactly the changes regarding of lipid peroxidation, antioxidant protection and the oxidative modification of proteins $[8,9]$.

Therefore, the challenge is to find new ways to treat the complications of diabetes. It is also important to take into account the maximum effectiveness and low cost of treatment. Exactly such methods of treatment include physical methods.

The finding effective and inexpensive therapies is one of the most important medical searches. And given that the number of patients with diabetes is increasing dramatically, so research into this area is extremely important to treat the complications of diabetes [10].

In the treatment of physical methods also use ozone therapy, because ozone has different properties, in partic- 
ular has a pronounced antibacterial effect, hematopoiesis, improves reparative processes and more. [11].

\section{THE AIM}

The aim of our work was to improve the course of purulent wounds in diabetes by using physical therapies.

\section{MATERIALS AND METHODS}

In our work, we had investigated 122 patients with diabetes mellitus and the wound processes. We had divided all patients on the two groups.

The our study groups were 50 patients who had therapy by ozone together with other general treatment and surgery treatment (daily dressings, ointments and solutions).

The our control groups were 72 patients, who had treated only by general methods and surgery treatment (daily dressings, ointments and solutions).

The patients of our explore group had received intravenous injection of saline ozone solution together with other general treatment and surgery treatment (daily dressings, ointments and solutions).

The patients our study groups had received ozone solution for 7-12 days.

The our control groups had had treated only by general methods and surgery treatment (daily dressings, ointments and solutions).

The presence of inflammatory processes was evaluated by the patient's admission to the hospital, at the time of receiving appropriate treatment, and at the time of recovery.

We had studied the levels of oxidative modification of proteins in blood plasma and the indicators of lipid peroxidation in blood plasma had studied too.

Also, to evaluate the effect of ozone therapy on the course of the wound process and to evaluate the effectiveness of this physical method of treatment in patients with purulent wounds in diabetes, we had evaluated the leukocyte index of intoxication. Were leukocyte index of intoxication was normal about $1,0 \pm 0,5$.

\section{RESULTS}

During the course of observation in the treatment of patients with complicated forms of diabetes mellitus, which in addition to conservative treatment, various surgical interventions were performed (resections and disarticulations of the phalanges of the fingers of the lower extremities, opening of the suppurative processes of the anterior abdominal wall and femur, shin area).

When we were studied of indicators of oxidative modification of proteins, lipid peroxidation in blood plasma, antioxidant protection during this period, there were no significant changes in these parameters between the control and experimental groups.

Therefore, it can be concluded according to this observation and study, given the absence of significant changes in the relevant indicators (oxidative modification of proteins, lipid peroxidation in blood plasma, antioxidant protection), that the use of ozone therapy in patients with complicated forms of diabetes does not adversely affect this link pathological process.

The course of changes in the indexes of intoxication was also studied: leukocyte index of intoxication, hematological index of intoxication and sorption capacity of erythrocytes in patients of the main and control groups.

As a result of the study (at the time of admission, during treatment, at the time of discharge), it was found that the leukocyte index of intoxication in patients in the main and control groups was almost indistinguishable.

Regarding the indexes of hematological index of intoxication, which decreased during the treatment of patients of the main group, and different from the patients of the control group, in which this indicator increased sharply.

The result of the study of changes in the indicators of sorption capacity of erythrocytes showed that the level of sorption capacity of erythrocytes in patients in the main group during treatment, also decreased, compared with patients in the control group.

The increase in hematologic index of intoxication in patients in the control group can be regarded as a significant sign of existing intoxication in the body. The decrease in these indicators in the patients of the base group makes it possible to consider this as a low level of intussusception syndrome.

\section{DISCUSSION}

Therefore, given the dynamic course of indicators of oxidative modification of proteins, lipid peroxidation in blood plasma, antioxidant protection during this period, there were no significant changes in these parameters between the control and experimental groups. And leukocyte index of intoxication, hematological index of intoxication and sorption capacity of erythrocytes in patients of the main and control groups [8].

As a result of the study (at the time of admission, during treatment, at the time of discharge), it was found that the leukocyte index of intoxication in patients in the main and control groups was almost indistinguishable. Regarding the indexes of hematological index of intoxication, which decreased during the treatment of patients of the main group, and different from the patients of the control group, in which this indicator increased sharply [2].

The result of the study of changes in the indicators of sorption capacity of erythrocytes showed that the level of sorption capacity of erythrocytes in patients in the main group during treatment, also decreased, compared with patients in the control group [6].

The increase in hematologic index of intoxication in patients in the control group can be regarded as a significant sign of existing intoxication in the body. The decrease in these indicators in the patients of the base group makes it possible to consider this as a low level of intussusception syndrome [4].

Therefore, all the obtained results indicate that the use of ozone as a physical method in the complex treatment of patients with complications of diabetes mellitus does not 
contribute to the negative impact of this method on the indexes of intoxication and homeostasis of blood. And it gives an opportunity to consider these results as a positive effect of ozone therapy in the complex treatment of patients with complicated forms of diabetes [5].

\section{CONCLUSIONS}

1. Therefore, the use of ozone in the treatment of patients with complicated forms of diabetes does not cause a negative impact on the dynamics of homeostasis and indicators of the level of intoxication of the body.

2. Ozone therapy has a beneficial effect on the course and wound process in patients with diabetes with purulent processes.

\section{REFERENCES}

1. Germanyuk T., Ivko I. Rational choice of monotherapy for the treatment of type 2 diabetes mellitus based on the pharmacoeconomical analysis. Science Rise. 2014; 4(5):69-72. doi: https://doi.org/10.15587/23138416.2014.32109.

2. Atkinson M., Herrath M., Powers A. et al. Current concepts of the pathogenesis of type 1 diabetes - considerations for attempts to prevent and reverse the disease. Diabetes Care. 2015;38:979-988. doi: $10.2337 / \mathrm{dc} 15-0144$

3. Bolli G., De Vries J. New long-acting insulin analogs: from damp studies to clinical practice. Diabetes Care. 2015; 38: 541-543. dol: 10.2174/157339911794273892.

4. Karatieieva S., Yurkiv 0., Semenenko S. Evaluation of the use of ozone therapy in the treatment of inflammatory processes in diabetes mellitus in an experiment. Georgian medical news. 2016;10(259): 58-61.

5. Karatieieva S., Makarova 0., Yurkiv 0. Treatment of pyoinflammatory complications in diabetic patients with individual selection of ozone dose. Gorgian medical news. 2018; 2(275):91-94.

6. Kumar S., Chakravarty B. ABC/VED analysis of expendable medical stores at atertiary care hospital. Med J Armed Forces India. 2015; 71:24-27.

7. Andrews M., $0^{\prime}$ Malley P. Diabetes overtreatment in eldery individuals: risky business in need of better management .JAMA. 2014; 311: 23262327. doi: 10.1001/jama.2014.4563

8. Giwa A., Tayo F. Cost-effectiveness analysis of anti-diabetic therapy in a university teaching hospital. International Journal of Pharma Sciences and Research (IJPSR) .2014; 03: 82 - 91.
9. Mishchenko 0., lakovlieva L., Adonkina V. Pharmacoeconomic evaluation of fxed - dose triple combination for antihypertensive therapy in Ukraine. Journal of Health Policy Outcomes Research. 2014; 1:66-74.

10. Mpondo B. Glycaemic control and glucose-lowering therapy in diabetic patients with kidney diseas. African Journal of Diabetes Medicine. 2014; 1: 12-16.

11. Sharma P., Sharma N., Parakh R. et al. Screening of prescriptions in patients of type -2 diabetes mellitus in a tertiary care teaching hospital. International journal of pharmaceutical research and bioscience. 2014; 3(1) : 401-409. doi: 10.20959/wjpps20173-8761

\section{ORCID and contributionship:}

Svitlana Y. Karatieieva: 0000-0003-1836-8337 ${ }^{A, B}$

Nataliia Y. Muzyka: 0000-0007-1976-8347 C,F

Karolina I. Yakovets: 0000-0002-1276-3337 ${ }^{B}$

Oksana V. Bakun: 0000-0008-1166-9544 ${ }^{D}$

Ksenia V. Slobodian: 0000-0005-1096-1092 ${ }^{E}$

\section{Conflict of interest:}

The Authors declare no conflict of interest.

\section{CORRESPONDING AUTHOR \\ Svitlana Yu. Karatieieva \\ Bukovinian State Medical University \\ 2 Theatralna str. 58002 Chernivtsi, Ukraine \\ tel: +380662670935 \\ e-mail: Karatsveta@gmail.com}

Received: 06.11 .2020

Accepted: 01.03.2021

A - Work concept and design, B - Data collection and analysis, C - Responsibility for statistical analysis,

D-Writing the article, $\mathbf{E}$-Critical review, $\mathbf{F}$ - Final approval of the article 